\title{
Oral and Facial Manifestations of Patients with Multiple Sclerosis
}

\section{Lassemi ${ }^{1}$, Sahraian MA², Motamedi MHK ${ }^{3 *}$, Valayi $\mathbf{N}^{4}$, Moradi $\mathbf{N}^{5}$ and Lasemi $\mathbf{R}^{6}$}

${ }^{1}$ Department of Oral and Maxillofacial Surgery, Azad University of Medical Sciences, Dental branch, Tehran, Iran

${ }^{2}$ Sina MS Research Center and Department of Internal Neurology, Sina Hospital, University of Medical Sciences, Tehran, Iran

${ }^{3}$ Department of Oral and Maxillofacial Surgery, Trauma Research Center, Baqiyatallah University of Medical Sciences and Azad University of Medical Sciences, Dental Branch, Tehran, Iran

${ }^{4}$ Member of Scientific Staff, Shahid Beheshti University of Medical Sciences and Azad University Dental branch, Tehran, Iran

${ }^{5}$ Private Practice Dentistry, Tehran, Iran

${ }^{6}$ Private Practice Medicine, Tehran, Iran

\author{
Abstract \\ Aim: With regard to the prevalence of Multiple Sclerosis and the importance of early diagnosis, we aimed to \\ assess the prevalence of oral and facial manifestations in patients with multiple sclerosis (MS).
}

Material and methods: This cross-sectional study assessed 400 MS patients for oral and facial manifestations. Trigeminal neuralgia, dysarthria, dysphagia, TMD, facial palsy and visual symptoms were documented. Occurrence of each manifestation was determined, its confidence interval was evaluated within a probability of $95 \%$, and the role of the related factors in this prevalence was analyzed with the Chi-square test.

Results: This study of 400 patients with MS revealed that $89.2 \%$ demonstrated oral and facial symptoms. The most frequent manifestations were visual symptoms (79.5\%), dysarthria (44.3\%), dysphagia (21\%), facial palsy (15.3\%), temporomandibular disorder (14.3\%) and trigeminal neuralgia (13.3\%). The related factors (individual and familial) showed no significant relation to the incidence of these manifestations.

Conclusion: This study revealed a high prevalence of oral and facial manifestations in MS patients and therefore the dentist may be the first to diagnose this.

Keywords: Multiple sclerosis; Trigeminal neuralgia; Dysarthria; Dysphagia; TMD; Facial palsy; Visual symptoms

\section{Introduction}

The high prevalence of multiple sclerosis (MS) in the northern hemisphere is of concern [1]. In this disease, discrete plaques of demyelization occur at sites throughout the CNS causes by a cellmediated immune response [2]. This chronic inflammatory disease is often progressive and attacks the myelin sheath of the CNS. MS is a destructive disease that affects the oral and maxillofacial complex as well. Oral and facial manifestation in MS patients, are significant for dentists especially trigeminal neuralgia (TN), trigeminal sensory neuropathy (TSN) and facial palsy (FP) [1]. As the prevalence of oral and facial manifestation in MS is high, the probability of MS can be raised, and thus preclude unnecessary treatment of these manifestations instead of the primary etiology [3].

\section{Materials and Methods}

This is a descriptive study (Cross-Sectional), which according to a pilot study on fifteen patients with MS that 6 patients (40\%) of those with oral and facial manifestations, with the confidence level about $90 \%$ and bias about 10\%, 400 patients admitted to the MS Society were studied. Samples by Sequential and go to the MS Society continue until the expected numbers achieved.

All patients had records in Iranian MS Society, and in all cases, a reasonable diagnosis based on exams by physician, Neurologist and MRI was prepared. Condition of patients in relation to the variables of age, sex, educational level, place of residence, duration of illness, the first symptom of MS, a history of drug use prior to developing MS, history of systemic disease, history of neurological disease, history of surgery, anesthesia and risk of MS in family members were examined (Table 1).

Six oral and facial disorders upon which patients have studied by neurologist were Trigeminal Neuralgia, Facial Palsy, TMD (Temporomandibular disorder), Dysphagia, Dysarthria and Visual
Symptoms. To diagnose Trigeminal Neuralgia with the history of facial pain, describing pain and the factors that trigger it, time and location of pain, from the patient has asked. To diagnose Facial Palsy by standard physical examination which was performed to determine if muscle function Expression, Grade FP involvement was based on the 0-4 rating which zero means no FP and 4 means complete FP.

Dysphagia assessment based assay system EDSS (Expanded Disability Status Scale) which was performed. TMD assessment of the moveable jaw mandible and the TMJ (temporomandibular joint) while the pain of the masticatory muscles have evaluated. Entire examinations based on RDC (Research diagnostic criteria) which those were for TMD, respectively [4]. Perimetry performed that using visual cues the presence or absence of pain, TMJ sounds (clicking, crepitus) and limitation of mouth opening, deviation of the mandible during opening and closing the mouth examined. It is Realize swallowing problems, a history of having difficulty swallowing and cough drop history aside portions of food or turning to soft foods have studied. The sound quality than the long and vibration, speed and power of speech, pronunciation of words and sentences correctly assessed and Dysarthria history have been determined by questionnaire. Patients with visual impairments view the questions related to blurred vision, double vision, movement and rapid involuntary eye, poor vision or complete loss of vision in the

*Corresponding author: Mohammad Hosein Kalantar Motamedi, Department of Oral and Maxillofacial Surgery, Azad University of Medical Sciences, Dental branch, Giti 16, Tehran, 19667 Iran, Tel: 009821 22616946, 00989121937154 E-mail: motamedical@lycos.com

Received December 16, 2013; Accepted January 10, 2014; Published January 12, 2014

Citation: Lassemi E, Sahraian MA, Motamedi MHK, Valayi N, Moradi N, et al. (2014) Oral and Facial Manifestations of Patients with Multiple Sclerosis. Dentistry 4: 194 doi: $10.4172 / 2161-1122.1000194$

Copyright: (C) 2014 Lassemi E. This is an open-access article distributed under the terms of the Creative Commons Attribution License, which permits unrestricted use, distribution, and reproduction in any medium, provided the original author and source are credited. 
past and present, identified. Finally recorded and classified data, the frequency of each oral and facial manifestations and the actual amount of them (Confidence Interval=CI) with probability 95\% from the population determined. Chi-Square examined the factors associated with the occurrence of these manifestations.

\section{Results}

The study of 400 MS patients revealed 292 (73\%) were female and $108(27 \%)$ male. The mean age of the patients under evaluation was $34 \pm 10.2$ years (8-64 years). Distribution of MS patients according to oral and facial manifestations presented in (Figure 1). Visual disorders (79.5\%) were the most common. The prevalence of other oral and facial MS manifestations included dysarthria (44.3\%), dysphagia (21\%), facial palsy (15\%), TMD (14.3\%) and trigeminal neuralgia (13.3\%), respectively. There were oral and facial manifestations in $89.9 \%$ of MS patients (Figure 1).

The role of factors such as age, sex, level of education, location, duration of MS involvement, medication before MS involvement, systemic disease, psychological disorder, history of general anesthesia, surgery and history of MS in the family had no significant relation with these manifestations (Table 1). Patients with oral symptoms and MS were more than 3 times those without oral and facial manifestation $(\mathrm{O} . \mathrm{R}=3)$. The Chi-Square showed that this difference were statistically significant $(\mathrm{R}<0.005)$.

Swallowing disorder in $90 \%$, speech disorder in $88 \%$, Trigeminal neuralgia in $70 \%$, facial palsy in $20 \%$ and visual disorder in $39 \%$ of patients appeared after MS diagnosis. While facial palsy and trigeminal neuralgia in $25 \%$ of patients had occurred before diagnosis of MS (Table 2).

\section{Discussion}

Our study showed there were oral and facial manifestations in $89.2 \%$ of MS patients. Visual disorders (79.5\%), speech disorders (44.3\%), swallowing problems (21\%), facial palsy (15.3\%), TMD (14.3\%) and TN (13.3\%) were noted. According to researchers, $68 \%-100 \%$ of MS patients have visual disorders [4-11]. There is no exist before even one article which is shown and studied all manifestations together or at least has not been available, Nevertheless, the question is that why should all of these symptoms seen in a single place ON? The answer to the reason that previous researchers have examined them separately $[4,5,7]$, indicating that each of these manifestations can be, Perhaps

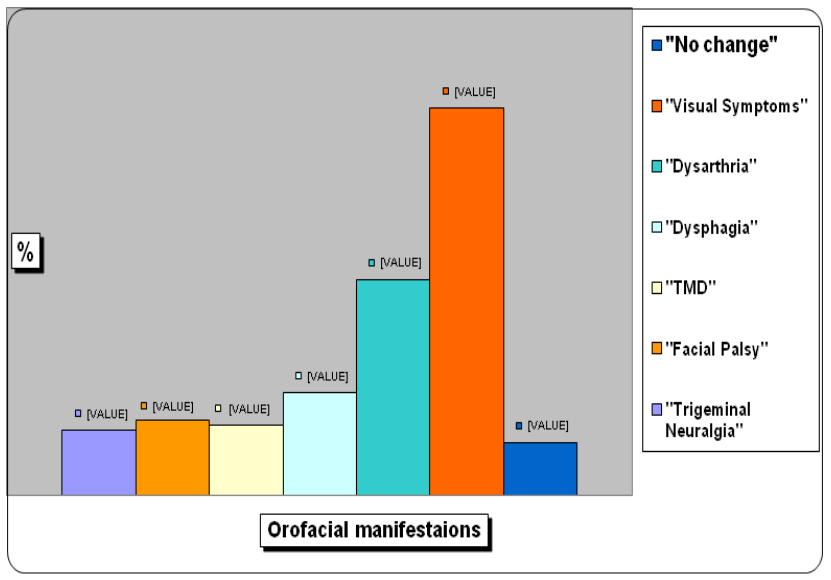

Figure 1: Distribution of oral manifestations in 400 patients with MS.

\begin{tabular}{|c|c|c|c|c|c|}
\hline O.R & $\begin{array}{c}\text { Result of } \\
\text { exams }\end{array}$ & $\begin{array}{c}\text { With } \\
\text { manifestations } \\
\text { N2 }=357\end{array}$ & $\begin{array}{c}\text { Without } \\
\text { manifestations } \\
\text { N1 }=43\end{array}$ & $\begin{array}{l}\text { Oral and facial } \\
\text { manifestations }\end{array}$ & ted Factors \\
\hline \multirow[t]{2}{*}{--- } & \multirow[t]{2}{*}{$\mathrm{P}<\cdot / 3$} & $189(53 \%)$ & $27(62.8 \%)$ & $\begin{array}{l}\text { Less than } 34 \\
\text { years }\end{array}$ & \multirow[t]{2}{*}{ age } \\
\hline & & $168(47 \%)$ & $16(37.2 \%)$ & Over 34 years & \\
\hline \multirow[t]{2}{*}{---} & $\mathrm{P}<\cdot / 9$ & $256(71.7 \%)$ & $36(83.7 \%)$ & Female & gender \\
\hline & & $101(28.3 \%)$ & $7(16.3 \%)$ & Male & \\
\hline \multirow[t]{2}{*}{3} & \multirow[t]{2}{*}{$\mathrm{P}<\cdot / 8$} & $173(48.5 \%)$ & $20(46.5 \%)$ & collegiate & \multirow{2}{*}{$\begin{array}{l}\text { Amount of } \\
\text { education }\end{array}$} \\
\hline & & $184(51.5 \%)$ & $23(53.5 \%)$ & Noncollegiate & \\
\hline \multirow[t]{5}{*}{----} & \multirow[t]{5}{*}{$\mathrm{P}<\cdot / 9$} & $47(13.2 \%)$ & $12(27.9 \%)$ & North & Life place \\
\hline & & $76(21.3 \%)$ & $6(14 \%)$ & South & \\
\hline & & $45(12.6 \%)$ & $7(16.3 \%)$ & East & \\
\hline & & $132(37 \%)$ & $12(27.9 \%)$ & West & \\
\hline & & 57 (15.9\%) & $6(13.9 \%)$ & Center & \\
\hline \multirow[t]{2}{*}{----} & \multirow[t]{2}{*}{$\mathrm{P}<\cdot / \cdot \cdot 5$} & $211(59.1 \%)$ & $35(81.4 \%)$ & 7 years and less & \multirow{2}{*}{$\begin{array}{l}\text { Duration of } \\
\text { MS }\end{array}$} \\
\hline & & $146(40.9 \%)$ & $8(18.6 \%)$ & Over 7 years & \\
\hline \multirow[t]{2}{*}{----} & \multirow[t]{2}{*}{$\mathrm{P}<\cdot / 9$} & 307 (86\%) & $36(83.7 \%)$ & No change & \multirow{2}{*}{$\begin{array}{l}\text { History of } \\
\text { using drugs } \\
\text { and } \\
\text { treatment } \\
\text { before MS }\end{array}$} \\
\hline & & $50(14 \%)$ & $7(16.3 \%)$ & With change & \\
\hline \multirow[t]{2}{*}{----} & \multirow[t]{2}{*}{$\mathrm{P}<\cdot / 7$} & $315(88.2 \%)$ & $37(86 \%)$ & No change & \multirow{2}{*}{$\begin{array}{l}\text { History of } \\
\text { systemic } \\
\text { diseases }\end{array}$} \\
\hline & & $42(11.8 \%)$ & $6(14 \%)$ & With change & \\
\hline \multirow[t]{2}{*}{----} & \multirow[t]{2}{*}{$\mathrm{P}<\cdot / 8$} & $330(92.4 \%)$ & $39(90.7 \%)$ & No change & \multirow{2}{*}{$\begin{array}{l}\text { History } \\
\text { of CNS } \\
\text { diseases } \\
\text { History }\end{array}$} \\
\hline & & $27(7.6 \%)$ & $4(9.3 \%)$ & With change & \\
\hline \multirow[t]{2}{*}{---} & \multirow[t]{2}{*}{$\mathrm{P}<\cdot / 9$} & $228(63.9 \%)$ & $32(74.4 \%)$ & No change & \multirow{2}{*}{$\begin{array}{l}\text { History of } \\
\text { surgery and } \\
\text { anesthesia }\end{array}$} \\
\hline & & $129(36.1 \%)$ & $11(25.6 \%)$ & With change & \\
\hline \multirow[t]{2}{*}{----} & \multirow[t]{2}{*}{$P<\cdot / 8$} & $311(87.1 \%)$ & $37(86 \%)$ & No change & \multirow{2}{*}{$\begin{array}{l}\text { Familial } \\
\text { history of } \\
\text { MS }\end{array}$} \\
\hline & & $46(12.9 \%)$ & $6(14 \%)$ & With change & \\
\hline
\end{tabular}

Table 1: Distribution of MS patients with oral and facial manifestations by separation of factors.

the first study of its kind to be all of these manifestations have been studied in one place. As stated visual disorders using questionnaires and observation, the rate of 79.5 percent, respectively. According to the researchers, the amount of 68 to 100 percent of patients with MS almost indistinguishable clinical examinations involves visual disorders [8]. Lycke in Sweden estimated 73\% visual symptoms based on neurological and ophthalmological and perimetry examinations [9]. Van Diemem et al. reported the prevalence of this disorder about $90.9 \%$ [11]. The prevalence of speech disorder in our study was $44.3 \%$, similar to a study from Sweden; it is $23 \%$ in the USA and $57 \%$ in South Africa [12]. These differences could be due to differences in the number of varieties and specifications samples, as well as the different types of tariffs and tools examined. 21 percent of MS patients in the study showed signs of dysphagia, which amount to less than 29 per cent hit De Pauw et al., 1991 in Belgium are 308 patients on his dysphagia gather information with the collection of and clinical, as well as prior to developing MS later evaluated [5]. According to the registration from previous studies, the prevalence of dysphagia in patients with MS from 33 to 43 percent have been reported in this study is that most of the statistics [5], in another study implemented by Poorjavad et al. in Isfahan. The frequency of dysphagia in patients with MS is about 31.7 percent have earned [13]. However, this variant can be due to different definitions of dysphagia and patient selection criteria. However, a lot of facial paralyses about $15.3 \%$ of our patients, which have found, are inconsistent with previous studies. Mr. Fukazawa has estimated the prevalence of facial palsy in 1997, on 107 Japanese patients with MS, 24.3 percent. 


\begin{tabular}{|c|c|c|c|}
\hline \begin{tabular}{|l|} 
Onset of manifestation \\
Diagnosis of MS made
\end{tabular} & $\begin{array}{c}\text { Oro facial manifestation } \\
\text { And number }\end{array}$ & Percentage & Number \\
\hline Before diagnosis & \multirow{3}{*}{$\begin{array}{c}\text { TN } \\
N 1=53\end{array}$} & $24.5 \%$ & 13 \\
\hline First sign & & $5.7 \%$ & 3 \\
\hline After diagnosis & & $69.8 \%$ & 37 \\
\hline Before diagnosis & \multirow{3}{*}{$\begin{array}{c}\mathrm{FP} \\
\mathrm{N} 2=61\end{array}$} & $24.6 \%$ & 15 \\
\hline First sign & & $13.1 \%$ & 8 \\
\hline After diagnosis & & $62.3 \%$ & 38 \\
\hline Before diagnosis & \multirow{3}{*}{$\begin{array}{l}\text { TMD } \\
\text { N3=57 }\end{array}$} & $38.6 \%$ & 22 \\
\hline First sign & & $0 \%$ & 0 \\
\hline After diagnosis & & $61.4 \%$ & 35 \\
\hline Before diagnosis & \multirow{3}{*}{$\begin{array}{l}\text { Dysphagia } \\
\text { N4=84 }\end{array}$} & $8.3 \%$ & 7 \\
\hline First sign & & $1.2 \%$ & 1 \\
\hline After diagnosis & & $90.5 \%$ & 76 \\
\hline Before diagnosis & \multirow{3}{*}{$\begin{array}{l}\text { Dysarthria } \\
\text { N5 }=177\end{array}$} & $9.6 \%$ & 17 \\
\hline First sign & & $2.3 \%$ & 4 \\
\hline After diagnosis & & $88.1 \%$ & 156 \\
\hline Before diagnosis & \multirow{3}{*}{$\begin{array}{l}\text { Visual Symptoms } \\
\text { N6=318 }\end{array}$} & $7 \%$ & 22 \\
\hline First sign & & $54 \%$ & 172 \\
\hline After diagnosis & & $39 \%$ & 124 \\
\hline
\end{tabular}

Table 2: Distribution of oral manifestations of MS patients and time of onset relative to MS diagnosis.

Whole of patients had careful clinical examination, MRI and CT brain scan in which shows accuracy of research [7]. Although in his study, he did not show the incidence of facial paralysis as a symptom of MS diagnosis, about 4.8 percent he could find facial palsy as the first symptom of MS patients in the present study, facial palsy as the first symptom of MS has shown in $13 \%$ of patients. The incidence of trigeminal neuralgia, the figures reported in previous studies, such as trigeminal neuralgia Osterberg et al. in Sweden, the frequency of trigeminal neuralgia 4.9 percent reported [10]. A study of the incidence of trigeminal neuralgia, before MS diagnosis was not available, however, it occurs as the first symptom of MS, 0.3 percent [1], which is the lesser of Statistics 5.7 percent at the first sign of this research. Within the TMD, prevalence obtained $14.3 \%$, which was much lower than the findings of previous research.

In sum, it appears that oral and facial manifestations in these patients was high and make a concern. Given the high prevalence of MS in Iranian society, a dentist must be familiar enough with all oral and facial manifestations of MS disease to avoid unnecessary and mistake treatments; furthermore, the dentist may be the first person who has a detection of disease. The destruction of myelin in MS patients may impair the rapid transmission of nerve signals. Areas in which myelin is destroyed, change to scar, or so-called MS plaques, arise depending on the location of these plaques, various symptoms of MS may occur [12]. Sclerotic plaques in the course of the trigeminal nerve, a branch existed, will cause trigeminal neuralgia [14]. MRI can see the plaque on the brain stem in patients with facial paralysis [8]. Involvement of the optic nerve in MS patients is common and often transient demyelination of the optic nerve that causes optic neuritis [12]. Similarly, the place and size of plaque, will determine the severity of dysarthria [15]. In case, there is agreement among researchers that dysphagia is associated with an increase in other general failures to show swallowing dysfunctions [5]. However, in the present study $8.3 \%$ of patients with swallowing disorders have been reported before certain diagnosis of MS. Research showed that the factors associated with disease only duration of MS (more than 7 years) has increased the risk of oral and facial manifestations. However, the question is why increasing the duration of MS, which make the manifestations increase? As we know the reason MS is unknown , an autoimmune inflammatory process, damaged myelin in the central nervous system, resulting in scar formation and disruption of the rapid transmission of nerve signals is in the manifestations followed MS disease occur [12]. Given the progressive nature of MS over time, with increasing damage, increasing manifestations of disease would be expected.

\section{Conclusion}

Oral and facial manifestation in MS patients is high. Dentists should be aware of all signs and symptoms of MS to prevent unnecessary treatments.

\section{References}

1. Chemaly D, Lefrançois A, Pérusse $R$ (2000) Oral and maxillofacial manifestations of multiple sclerosis. J Can Dent Assoc 66: 600-605.

2. Tweedle JA, Morrissey JB, RankowRM (1970) Mistaken TMJ pathology in unrecognized multiple sclerosis: report of case. J Oral Surg 28: 785-788.

3. Fiske J, Griffiths J, Thompson S (2002) Multiple sclerosis and oral care. Dent Update 29: 273-283.

4. Kovac Z, Uhac I, Buković D, Cabov T, Kovacević D, et al. (2005) Oral health status and temporomandibular disorders in multiple sclerosis patients. Coll Antropol 29: 441-444.

5. De Pauw A, Dejaeger E, D'hooghe B, Carton H (2002) Dysphagia in multiple sclerosis. Clin Neurol Neurosurg 104: 345-351.

6. Peres DS, Diniz DS, Silva PP, Ribeiro TG (2005) Evaluation of swallowing \& TMD in 31 patients with Multiple Sclerosis. Federal University of Goias, Goiania, Brazil.

7. Fukazawa T, Moriwaka F, Hamod K (1997) Facial Palsy in Multiple Sclerosis. J Neurol 244: 631633

8. Sisto D, Trojano M, Vetrugno M, Trabucco T, lliceto G, et al. (2005) Subclinical visual involvement in multiple sclerosis: a study by MRI, VEPs, frequencydoubling perimetry, standard perimetry, and contrast sensitivity. Invest Ophthalmol Vis Sci 46: 1264-1268.

9. Lycke J, Tollesson PO, Frisén L (2001) Asymptomatic visual loss in multiple sclerosis. J Neurol 248: 1079-1086.

10. Osterberg A, Boivie J, Thuomas KA (2005) Central pain in multiple sclerosisprevalence and clinical characteristics. Eur J Pain 9: 531-542.

11. Van Diemen HA, Lanting P, Koetsier JC (1992) Evaluation of the visual system in Multiple Sclerosis: a comparative study of diagnostic tests. Clin Neural Neurosurg 94: 191195.

12. Roger PS, David AG, Michael JA (2009) Clinical Neurology. (7thedn), McGrawHill.

13. Poorjavad M, Derakhshandeh F, Etemadifar M, Soleymani B, Minagar A, et al. (2010) Oropharyngeal dysphagia in multiple sclerosis. Mult Scler 16: 362-365.

14. Desaloms JM (2002) Comprehensive Management of Trigeminal Neuralgia Presbyterian Hospital of Dallas Texas Health Resources. Interactive CME series covering advances in neurosciences.

15. Burks JS, Johnson KP (2000) Multiple sclerosis: diagnosis, medical management, and rehabilitation. (1stedn), Demos Medical Publishing. 